\title{
Kadar Fenolik dan Flavonoid Total Ekstrak Etanol Daun Anggur (Vitis vinifera $L$ )
}

\section{Total Phenolic and Flavonoid Content of Grapevine (Vitis vinifera L) Leaves Ethanol Extract}

\author{
Mukhriani $^{1 *}$, Ratna Sugiarna ${ }^{2}$, Nadhila Farhan ${ }^{2}$, Muh Rusdi $^{1}$, Muh Ikhlas Arsul ${ }^{1}$, \\ ${ }^{1}$ Jurusan Farmasi Fakultas Kedokteran dan Ilmu Kesehatan Universitas Islam Negeri Alauddin Makassar, \\ Jl H.M. Yasin Limpo No.36 Kecamatan Sombaopu Kabupaten Gowa, Sulawesi Selatan \\ ${ }^{2}$ Mahasiswa Prodi Farmasi Fakultas Kedokteran dan Ilmu Kesehatan Universitas Islam Negeri Alauddin \\ Makassar, Jl H.M. Yasin Limpo No.36 Kecamatan Sombaopu Kabupaten Gowa, Sulawesi Selatan
}

Kontak sur-el*: fm.tetty@gmail.com

\begin{abstract}
ABSTRAK
Telah dilakukan penelitian mengenai analisis kadar fenolik dan flavonoid total ekstrak daun anggur (Vitis vinifera $L$ ) dengan metode Spektrofotometri UV-Vis. Penelitian ini bertujuan untuk menentukan kadar fenolik dan flavonoid total dalam ekstrak etanol daun anggur. Sampel diekstraksi dengan metode maserasi menggunakan pelarut etanol. Penentuan kadar fenolik total ekstrak menggunakan pembanding asam galat dengan beberapa variasi konsentrasi. Penentuan kadar flavonoid total menggunakan pembanding kuersetin. Nilai absorbansi diukur dengan spektrofotometer. Nilai absorbansi kemudian dimasukkan ke dalam persamaan regresi linier. Hasil penelitian menunjukkan kadar total fenolik dan kadar total flavonoid dalam ekstrak berturut-turut adalah sebesar 95,28 $\mathrm{mg}$ $G A E / \mathrm{g}$ dan $4,07 \mathrm{mg} Q E / \mathrm{g}$.
\end{abstract}

Kata Kunci : Vitis vinifera, maserasi, kadar fenolik total, kadar flavonoid total

\section{ABSTRACT}

Studies on the analysis of the total phenol and flavonoid content of grapevine leaf extract (Vitis vinifera L) using UV-Vis spectrophotometry has been researched. The aim of this study is to determine the total content of phenol and flavonoids in the ethanol extract from leaves of Vitis vinifera $L$. The samples were extracted using the maceration method with ethanol as the solvent. Determination of total phenol content of extract using a gallic acid as standard with various concentration variations. Determination of total flavonoid content using quercetin as standard. Absorbances measured with spectrophotometer. Absorbances values then inserted a linear regression equation. The results showed that the total phenol and flavonoid contents of extract were, respectively, 95,28 $\mathrm{mg}$ $G A E / g$ and $4.07 \mathrm{mg} Q E / g$.

Keywords : Vitis vinifera, maserasi, total phenolic content, total flavonoid content

\section{PENDAHULUAN}

Anggur kaya akan senyawa golongan flavonoid dan fenolik. merupakan tanaman yang tumbuh merambat, serta memiliki keistimewaan dengan ranting-rantingnya yang dapat mengeluarkan buah yang lebat (Nurcahyo, 1999). Senyawa utama yang terdapat dalam tanaman anggur adalah flavonoid proantosianidin, antosianin dan flavonol. Dalam kulit anggur, flavonol ditemukan sebagai glikosida dari kaempferol, kuersetin, mirisetin dan isoramnetin. Sedangkan biji anggur mengandung flavan-3ols termasuk (+)katekin, (-)epikatekin, (-)epikatekin-3-O-galat, baik sebagai monomer maupun polimer proantosianidin. 
Kulit anggur memiliki konsentrasi flavan-3-ol (monomer dari proantosianidin yang mengandung (-) epigalokatekin) lebih rendah jika dibandingkan dengan biji anggur (Cortel \& Kennedy, 2006). Menurut Farmakope Prancis, daun anggur kering harus mengandung setidaknya $4 \%$ polifenol total dan $0,2 \%$ antosianin (Chinou, 2016).

Polifenol merupakan salah satu komponen fitokimia yang terkandung dalam tanaman anggur memiliki beberapa aktivitas farmakologi. Kandungan ini memiliki berkhasiat seperti menghambat penyakit jantung, kanker, mengurangi oksidasi plasma serta memperlambat penuaan. Selain itu tanaman anggur juga memiliki efek antioksidan, antiinflamasi, dan antimikroba. Senyawa fenol mempunyai peranan yang sangat penting sebagai antioksidan dalam buah dan sayuran. Kandungan senyawa fenol paling besar ditemukan pada kulit, stem, daun dan biji dari anggur (Xia, Deng, Guo, \& Li, 2010).

Flavonoid dalam Anggur juga berkhasiat farmakologis. Artanti (2006) menyatakan bahwa sejumlah tanaman obat yang mengandung flavonoid telah dilaporkan memiliki aktivitas antioksidan, antibakteri, antivirus, antiradang, antialergi dan anti kanker.

Kandungan fenolik yang terkandung dalam suatu tumbuhan dinyatakan sebagai $G A E$ (galic acid equivalent) yaitu jumlah kesetaraan milligram asam galat $(3,4,5-$ trihydroxybenzoic acid) dalam satu gram sampel. Sedangkan kandungan senyawa flavonoid (2-[3,4-dihydroxyphenyl]-3,5,7trihydroxy-4H-chromen-4-one) yang diukur menggunakan standar kuersetin, dihitung sebagai $Q E$ (quercetin equivalent) (Sari, 2017). Asam galat dan kuersetin memiliki khasiat utamanya sebagai antioksidan. Ekuivalen asam galat dan ekuivalen kuersetin merupakan acuan umum untuk mengukur jumlah senyawa golongan fenolik dan flavonoid yang terdapat dalam suatu sampel atau bahan (Lee, Kim, Lee, \& Lee, 2003).

Beberapa varietas buah anggur memiliki kandungan senyawa fenolik dan flavonoid yang berbeda-beda. Kadar fenolik totalnya antara 95,3 - 686,5 mg GAE/100 g buah. Sedangkan flavonoid total antara 94,7 - 1055 mg Catechin Equivalent/100 g buah (Liang, Cheng, Zhong, \& Liu, 2014).

\section{METODE PENELITIAN}

\section{Pengambilan Sampel}

Sampel daun anggur yang diperoleh dari Kabupaten Maros Sulawesi Selatan dicuci bersih. Setelah itu sampel dikeringkan dalam lemari pengering pada suhu $\pm 40^{\circ} \mathrm{C}$. Daun anggur yang kering dibuat serbuk dan disimpan dalam wadah kering.

\section{Ekstraksi}

Sebanyak 400 g serbuk kering dimaserasi selama 3 x 24 jam pada suhu kamar menggunakan pelarut etanol sebanyak 4000 ml. Penyaringan dilakukan dengan corong Buchner dan ampas dimaserasi dua kali lagi 
dengan cara yang sama kemudian disaring. Filtrat digabung dan diuapkan dengan rotavapor hingga diperoleh ekstrak kental.

\section{Identifikasi Senyawa Fenolik}

Larutan uji berupa hasil ekstraksi dimasukkan dalam tabung reaksi. Larutan uji ditambahkan pereaksi $\mathrm{FeCl}_{3} \quad 3 \%$ dalam pelarut etanol sebanyak 3 tetes dan diamati perubahan warnanya. Hasil positif ditunjukkan dengan adanya warna hijau, merah, ungu, biru atau hitam (Tiwari, Kumar, Kaur, Kaur, \& Kaur, 2011).

\section{Identifikasi Senyawa Flavonoid}

Ekstrak sebanyak $1 \mathrm{mg}$ dimasukkan dalam tabung reaksi dan dilarutkan dalam $2 \mathrm{ml}$ metanol 50\%. Setelah itu ditambahkan serbuk logam magnesium dan 4-5 tetes $\mathrm{HCl}$ pekat. Hasil positif jika terbentuk larutan berwarna merah bata.

\section{Penetapan Kadar Fenolik Total}

Kandungan fenolik didasarkan pada kurva absorbansi dari larutan standar asam galat. Larutan standar 1000 ppm dibuat dengan cara 10,0 mg asam galat ditimbang kemudian dilarutkan dengan etanol p.a hingga volume akhir 10,0 ml. Dari larutan stok tersebut dipipet sebanyak 2,5 $\mathrm{mL}$ diencerkan dengan etanol p.a hingga volume $25,0 \mathrm{~mL}$ sehingga dihasilkan konsentrasi 100 ppm. Dari larutan tersebut dibuat seri konsentrasi 10, 20, 30, 40 dan 50 ppm. Masing-masing konsentrasi larutan asam galat diambil sebanyak 5,0 ml dan ditambahkan dengan $0,4 \mathrm{ml}$ pereaksi folin-cioceltaeu lalu dikocok dan dibiarkan sekitar 4-8 menit. Lalu ditambahkan $3 \mathrm{ml}$ larutan $\mathrm{Na}_{2} \mathrm{CO}_{3} \quad 7 \%$ dan dikocok hingga homogen dan dicukupkan dengan air suling hingga 10,0 ml. Campuran didiamkan selama 2 jam pada suhu kamar kemudian diukur absorbansinya pada panjang gelombang maksimal 744,8 nm dengan Spektrofotometer $\mathrm{UV}-\mathrm{Vis}$.

Pengujian kandungan fenolik total sampel dimulai dengan melarutkan 10,0 mg ekstrak etanol daun anggur dengan etanol p.a hingga diperoleh volume akhir 10,0 ml. Larutan sampel kemudian direaksikan dengan prosedur yang sama dengan larutan standar asam galat. Seluruh pengukuran absorbansi dilakukan sebanyak tiga kali.

\section{Penetapan Kadar Flovonoid Total}

Kandungan flavonoid didasarkan pada kurva absorbansi dari larutan standar kuersetin. Larutan standar dibuat dimulai dengan melarutkan 25,0 mg baku standar kuersetin dalam etanol hingga volume 25,0 ml dan diperoleh konsentrasi 1000 ppm. Dari larutan stok tersebut dipipet $1,0 \mathrm{ml}$ lalu dicukupkan volumenya sampai 10,0 ml. Dari larutan standar kuersetin 100 ppm, kemudian dibuat beberapa seri konsentrasi yaitu 4, 6, 8, 10, dan 12 ppm. Kemudian masing-masing konsentrasi larutan standar kuersetin sebanyak 5,0 ml ditambahkan $3 \mathrm{ml}$ etanol, 0,2 $\mathrm{ml} \mathrm{AlCl}_{3} 10 \%$ dan $0,2 \mathrm{ml}$ kalium asetat $1 \mathrm{M}$. Setelah itu sampel diinkubasi selama 30 menit pada suhu kamar. Campuran diukur 
absorbansinya pada spektrofotometer UV-Vis dengan panjang gelombang $440 \mathrm{~nm}$.

Kandungan flavonoid total merujuk pada prosedur Chang, Yang, Wen, \& Chern (2002) menggunakan kuersetin sebagai standar. Ditimbang ekstrak sebanyak $25 \mathrm{mg}$ dan dilarutkan dalam 25,0 $\mathrm{ml}$ etanol. Larutan sampel kemudian direaksikan dengan prosedur yang sama dengan larutan standar kuersetin. Pengukuran dilakukan sebanyak tiga kali.

\section{Analisis Data}

Analisis data menggunakan persamaan regresi linear yang dihitung dengan program Microsoft Excel sehingga diperoleh persamaan linier standar dari kurva absorbansi (y) vs konsentrasi (x). Konsentrasi fenolik dan flavonoid dari larutan sampel dihitung berdasarkan persamaan linier standar.

Perhitungan kadar fenolik (PH) dan flavonoid $(\mathrm{F})$ total dihitung dengan rumus berikut:

$$
\text { PH atau } F=\frac{c \cdot v \cdot f p}{g}
$$

dimana, $\mathrm{c}=$ konsentrasi sampel, $\mathrm{v}=$ volume ekstrak yang digunakan, $\mathrm{fp}=$ faktor pengenceran, dan $\mathrm{g}=$ berat sampel

\section{HASIL DAN PEMBAHASAN}

Tanaman anggur merupakan salah satu tanaman yang memiliki banyak manfaat baik dari segi buah, biji dan daunnya. Anggur memiliki fungsi sebagai antikaries, antiketombe, antifungi, antimikroba,
Tabel 1. Hasil uji pendahuluan ekstrak

\begin{tabular}{cccc}
$\begin{array}{c}\text { Uji } \\
\text { golongan }\end{array}$ & Pereaksi & Warna & $\begin{array}{c}\text { Kesim- } \\
\text { pulan }\end{array}$ \\
\hline Fenolik & $\mathrm{FeCl}_{3}$ & $\begin{array}{c}\text { Hijau } \\
\text { kehitaman }\end{array}$ & + \\
\hline Flavonoid & $\begin{array}{c}\mathrm{Mg}+ \\
\mathrm{HCl}\end{array}$ & $\begin{array}{c}\text { Merah } \\
\text { bata }\end{array}$ & + \\
\hline
\end{tabular}

antioksidan, bahan flavor, light stabilizer, dan sunscreen. Manfaat lain dari daun anggur adalah sebagai antibakteri. Kandungan senyawa yang terdapat dalam daun anggur untuk mengobati infeksi bakteri (Papadopoulou, Soulti, \& Roussis, 2005). Dalam penelitian sebelumnya, senyawa fenolik dan flavonoid diketahui memiliki berbagai efek biologis sebagai antioksidan, melindungi struktur sel, antiinflamasi, dan sebagai antiseptik (Xia, Deng, Guo, \& Li, 2010).

Hasil (tabel 1) menunjukkan bahwa ekstrak etanol daun anggur positif mengandung senyawa fenolik dan flavonoid yang ditandai dengan perubahan warna menjadi hijau kehitaman dan kuning. Identifikasi senyawa fenolik dilakukan dengan menggunakan larutan $\mathrm{FeCl}_{3}$. Ion $\mathrm{Fe}^{3+}$ akan bereaksi dengan gugus fenolik yang berada pada sampel membentuk warna hijau, biru, atau hitam, sebagai petunjuk adanya senyawa fenolik (Xia, Deng, Guo, \& Li, 2010). Reaksi dapat dilihat pada gambar 1. Untuk identifikasi senyawa flavonoid penambahan logam $\mathrm{Mg}$ dan $\mathrm{HCl}$ pada senyawa flavonoid bertujuan untuk mereduksi inti benzopiron yang terdapat dalam struktur flavonoid sehingga terjadi perubahan warna 


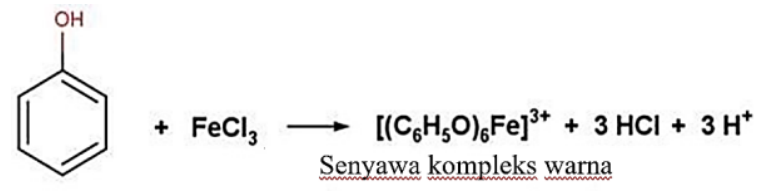

Gambar 1. Reaksi senyawa fenol dengan $\mathrm{FeCl}_{3}$<smiles>O=C1C(O)=C(c2ccccc2)OC2C=CC=CC12</smiles>

Flavanol<smiles>OC1=C(O)C2C=CC=CC2OC1c1ccccc1</smiles>

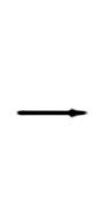<smiles>OC1=C(c2ccccc2)OC2C=CC=CC12</smiles><smiles>OC1=C(c2ccccc2)OC2C=CC=CC12</smiles>

Senyawa garam merah

Gambar 2. Reaksi senyawa flavonoid dengan $\mathrm{Mg}$ dan $\mathrm{HCl}$

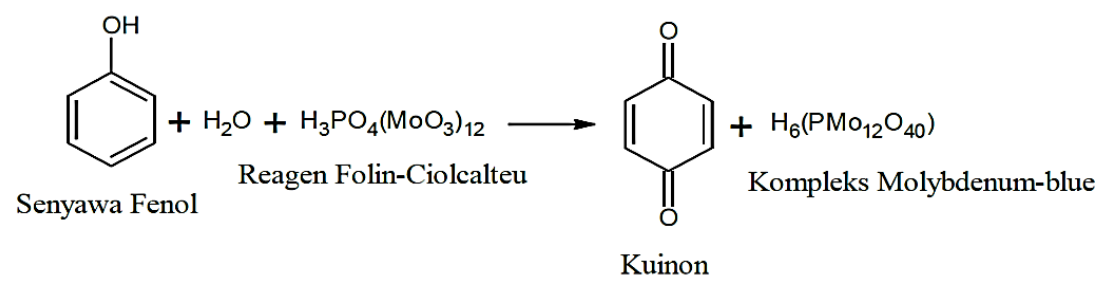

Gambar 3. Reaksi senyawa fenol dengan reagen folin ciocalteu.

jingga atau merah (lihat gambar 2). fenolik total adalah larutan $\mathrm{Na}_{2} \mathrm{CO}_{3}(\mathrm{Xia}$,

Penambahan $\mathrm{HCl}$ mengakibatkan reaksi oksidasi reduksi antara logam $\mathrm{Mg}$ sebagai pereduksi dengan senyawa flavonoid.

Penelitian ini dilakukan untuk menentukan kadar senyawa fenolik total pada daun anggur dengan menggunakan asam gallat. Senyawa ini merupakan salah satu senyawa fenol alami turunan asam hidroksibenzoat. Asam galat direaksikan dengan Folin-Ciocalteu dalam suasana basa menghasilkan warna hijau kehitaman yang menandakan positif atau mengandung fenol. Senyawa fenolik direaksikan dalam suasana basa agar terjadi disosiasi proton menjadi ion fenolat. Reaksi senyawa fenol dengan Folin-Ciocalteu dapat dilihat pada gambar 3. Larutan basa yang ditambahkan dalam penetapan kadar senyawa
Deng, Guo, \& Li, 2010).

Berdasarkan grafik (gambar 4) bahwa kurva kalibrasi dengan persamaan regresi untuk absorbasi asam galat adalah $\mathrm{y}=$ $0,0042 x+0,0625$. Sedangkan pada penentuan kurva kalibrasi kuersetin (gambar 5) diperoleh persamaan regresi $\mathrm{y}=0,0505 \mathrm{x}+$ 0,0468. Pada persamaan kurva baku kuersetin dan asam galat diperoleh hubungan yang linear antara absorbansi dengan konsentrasi dengan nilai koefisien korelasi sebesar >0,98. Nilai (R) yang mendekati satu menunjukkan bahwa persamaan regresi tersebut adalah linear. Perhitungan ini berdasarkan hukum Lambert-Beer yang menunjukkan hubungan antara peningkatan kadar analit terhadap kenaikan absorbansi. 
Tabel 2. Absobansi kurva kalibrasi asam galat

\begin{tabular}{ccccc}
\hline Konsentrasi & \multicolumn{4}{c}{ Absorbansi } \\
\cline { 2 - 5 } & 1 & 2 & 3 & Rata-rata \\
\hline 10 & 0,105 & 0,107 & 0,109 & 0,107 \\
20 & 0,149 & 0,151 & 0,156 & 0,152 \\
30 & 0,178 & 0,174 & 0,176 & 0,176 \\
40 & 0,225 & 0,227 & 0,229 & 0,227 \\
50 & 0,278 & 0,280 & 0,280 & 0,279 \\
\hline
\end{tabular}

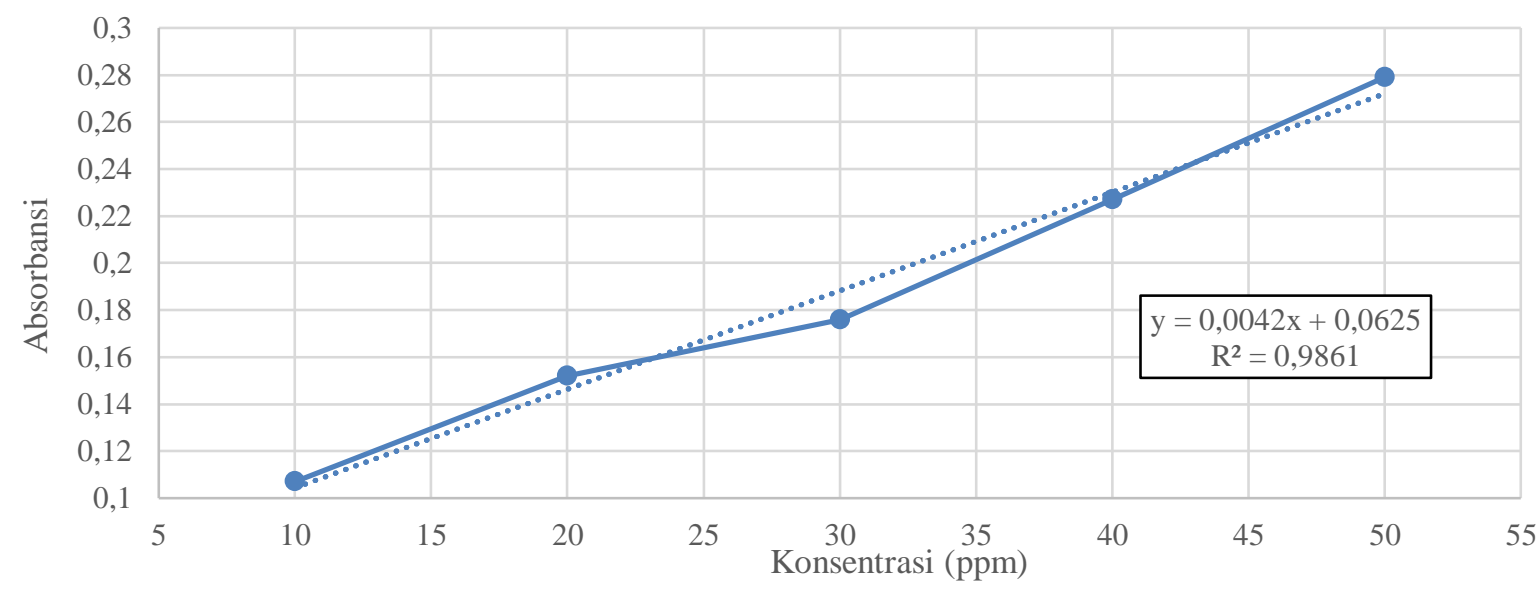

Gambar 4. Kurva standar asam galat.

Tabel 3. Absorbansi kurva kalibrasi kuersetin

\begin{tabular}{ccccc}
\hline Konsentrasi & \multicolumn{4}{c}{ Absorbansi } \\
\cline { 2 - 5 } & 1 & 2 & 3 & Rata-rata \\
\hline 4 & 0,248 & 0,240 & 0,234 & 0,240 \\
6 & 0,350 & 0,348 & 0,346 & 0,348 \\
8 & 0,482 & 0,480 & 0,478 & 0,480 \\
10 & 0,533 & 0,540 & 0,529 & 0,534 \\
12 & 0,656 & 0,642 & 0,662 & 0,653 \\
\hline
\end{tabular}

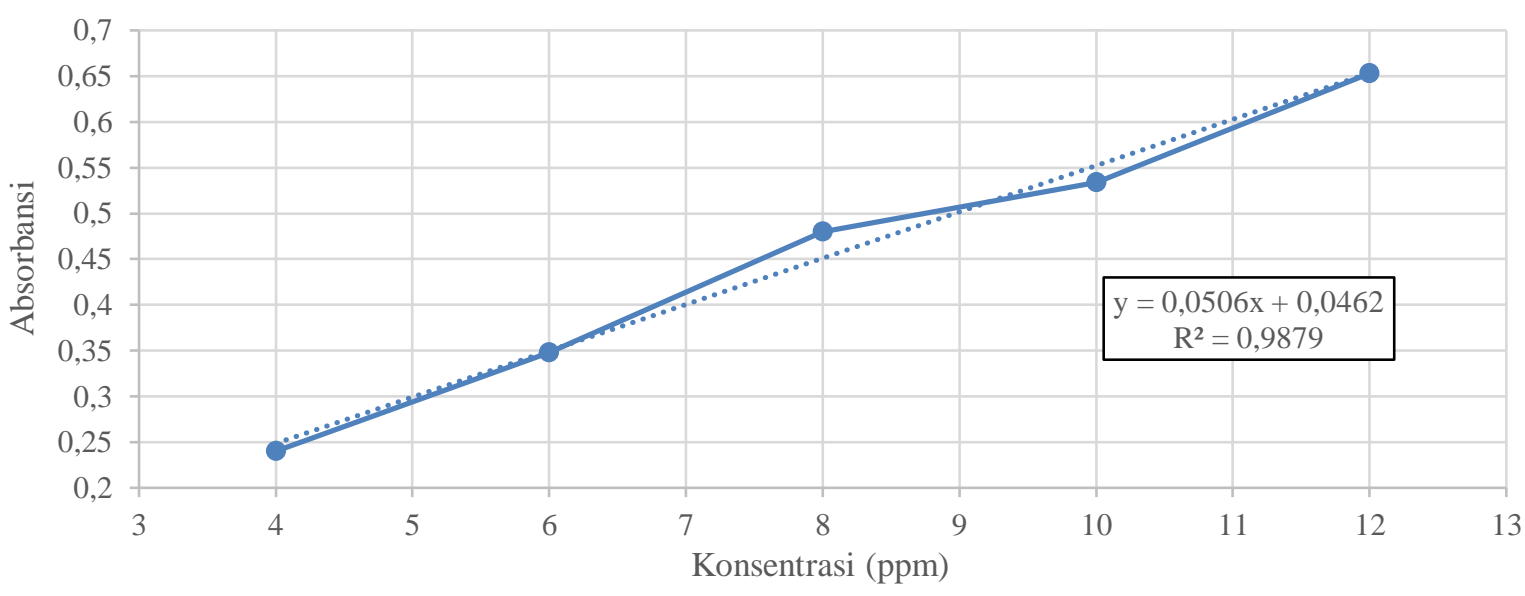

Gambar 5. Kurva standar kuersetin

Hasil dari pengukuran kadar fenolik dan flavonoid total ekstrak etanol daun anggur (tabel 4 dan 5) berturut-turut adalah sebesar
95,28 mg GAE/g ekstrak dan 4,07 mg $Q E / \mathrm{g}$ ekstrak. Kadar fenolik dan flavonoid yang telah dilaporkan Liang, Cheng, Zhong, \& Liu 
Tabel 4. Kandungan fenolik total

\begin{tabular}{cccc}
\hline Berat bahan $(\mathrm{g})$ & Absorbansi & Absorbansi rata-rata & Kadar fenolik total (mg GAE/g ekstrak) \\
\hline \multirow{3}{*}{0,01} & $\frac{0,347}{0,314}$ & 0,336 & 95,277 \\
\cline { 2 - 2 } & 0,348 & & \\
\hline
\end{tabular}

Tabel 5. Kandungan flavonoid total

\begin{tabular}{cccc}
\hline Berat bahan $(\mathrm{g})$ & Absorbansi & Absorbansi rata-rata & Kadar flavonoid total (mg QE/g ekstrak) \\
\hline \multirow{3}{*}{0,025} & $\frac{0,268}{0,235}$ & 0,252 & 4 \\
\cline { 2 - 2 } & 0,254 & 069 &
\end{tabular}

(2014) yaitu 0,95 - 6,865 mg GAE/g dan 0,947 - 10,55 mg Catechin Equivalent/g untuk sampel buah. Kandungan dalam sampel ekstrak tentu saja lebih besar dari pada sampel buah yang tidak diekstraksi. Selain itu, perbedaan dalam pengamatan ini sebagian besar tentu dikaitkan dengan varietas yang digunakan dalam penelitian, lokasi pengambilan sampel, proses perawatan tanaman dan prosedur analisis.

\section{KESIMPULAN}

Ekstrak etanol daun anggur positif mengandung senyawa fenolik dan flavonoid. Kadar fenolik total ekstrak etanol sebesar 95,277 mg GAE/g dan flavonoid total sebesar 4,069 mg $Q E / g$.

\section{DAFTAR PUSTAKA}

Artanti, M. (2006). Isolation and identification of active antioxsidant compound from star fruit. Journal of applied sciences, 1659-1663.

Chang, C., Yang, M., Wen, H., \& Chern, J. (2002). Estimation of Total Flavonoid Content in Propolis by Two Complementary Colorimetric Methods. Journal of Food and Drug Analysis, 10(3), 178-182.

Chinou, I. (2016). Assessment Report on Vitis vinifera L., Folium. London: European
Medicines Agency, Science Medicine Health. Retrieved from https://www.ema.europa.eu/en/documents/ herbal-report/draft-assessment-report-vitisvinifera-l-folium_en.pdf

Cortel, J., \& Kennedy, J. (2006). Effect of Shading on Accumulation of Flavonoid Compounds in (Vitis vinifera L.) Pinot Noir Fruit and Extraction in a Model System. J. Agric Food Chem, 54(22), 8510-20.

Lee, K., Kim, Y., Lee, H., \& Lee, C. (2003). Cocoa Has More Phenolic Phytochemical and Higher Antioxidant Capacity than Teas and Red Wine. J. Agric. Food Chem, 51, 7292-7295.

Liang, Z., Cheng, L., Zhong, G., \& Liu, R. (2014). Antioxidant and Antiproliferative Activities of Twenty-Four Vitis vinifera Grapes. PLoS One, e105146. doi:10.1371//journal.pone.0105146

Nurcahyo, E. (1999). Anggur Dalam Pot. Jakarta: Penebar Swadaya.

Papadopoulou, C., Soulti, K., \& Roussis, I. (2005). Potential Antimicrobial Activity of Red and White Wine Phenolic Extracts against Strains of Staphylococcus aureus,Escherichia coli and Candida albicans. Food Technology and Biotechnology, 547579616-92.

Sari, N. (2017). Penentuan Kadar Total Fenol dan Total Flavonoid dari Ekstrak Etanol Buah Andaliman (Zanthoxylum acanthopodium DC.). Sumatra Utara: Repositori Institusi USU. Retrieved from http://repositori.usu.ac.id/bitstream/handle/ 123456789/12813/121501075.pdf?sequenc $\mathrm{e}=1 \&$ is Allowed $=\mathrm{y}$ 
Tiwari, P., Kumar, B., Kaur, M., Kaur, G., \& Kaur, H. (2011). Phytochemical screening and Extraction: A Review. Internationale Pharmaceutica Sciencia, 98-106.

Xia, E., Deng, G., Guo, Y., \& Li, H. (2010). Biological Activities of Polyphenol from Grapes. Int. J. Mol. Sci, 11. 